\title{
To Share or Not to Share? How Emotional Judgments Drive Online Political Expression in High-Risk Contexts
}

\section{Aysenur Dal' (iD) and Erik C. Nisbet ${ }^{2}$}

\begin{abstract}
Previous scholarship on networked authoritarianism has examined an array of repressive legal and political strategies employed by regimes to constrain online political expression. How the tension between citizens' desires to engage in online political expression and the possible dire consequences of doing so is resolved, however, is understudied. We address this lacuna by drawing upon concepts from risk and decision-making research and examining how the emotional and cognitive components of risk and decision-making shape citizens' online political expression. Employing a three-wave panel survey of Turkish internet users collected over 8 months, our fixed-effects regression analyzes show that anticipatory emotions drive expressive behavior, but that risk assessment does not. Furthermore, the influence of negative emotions on online expression is moderated by individuals' degree of regime opposition. We discuss the importance of understanding the psychological mechanisms by which networked authoritarian contexts influences citizens' decisions to engage in contentious online speech.
\end{abstract}

\section{Keywords}

emotions, risk, social media, networked authoritarianism, political expression

\footnotetext{
'Bilkent University, Ankara, Turkey

${ }^{2}$ Northwestern University, Evanston, IL, USA

Corresponding Author:

Aysenur Dal, Department of Communication and Design, Bilkent University, Ankara, 06800, Turkey. Email: aysenur.dal@bilkent.edu.tr
} 
When a Turkish physician shared a meme juxtaposing the Turkish president with a character from Tolkien's The Lord of the Rings, he probably did not foresee losing his job and a 2-year prison sentence for an online post (Tremblay, 2015). The Turkish government's underlying public message was that no matter how trivial your online dissent, you are at risk of legal or political sanction. Government action of this kind limiting citizens' political expression is representative of the larger trend of governments around the world taking active measures to suppress online dissent.

Social networking sites' (SNSs) ability to amplify otherwise marginalized voices via digitally-mediated activities requiring minimum levels of effort, time, and commitment has become a target for governments who do not tolerate dissenting discourse (e.g., Gunitsky, 2015; Morozov, 2011). Networked authoritarian governments (MacKinnon, 2011) feel the need to control and intimidate through surveillance, censorship, and/or demonization of technologies those who criticize the regime and express grievances online. (e.g., MacKinnon, 2012; Roberts, 2020; Rod \& Weidmann, 2015). Citizens living in such environments, as a consequence, face the increasing risk of being punished by their governments for "low-cost" (i.e., easy to perform regardless of its consequences) online political activities.

The vast majority of global internet users reside in countries where citizens had been arrested or imprisoned for posting on political, social or religious issues (Freedom House, 2019). At the same time, data from 38 countries surveyed by the Pew Research Institute (2015) shows that globally $80 \%$ of citizens believe that people should be able to criticize their government openly and that it is important for people to use the Internet without state censorship.

Despite this discrepancy, the most studies examining drivers of individual online political expression (OPE) focus on populations in democratic political contexts that enjoy relatively low levels of legal, political, and physical risks associated with their online behavior. This creates a disconnect as most OPE takes place in political contexts experiencing the opposite with high levels of risk associated with the behavior. This gap is a symptom of what many in the academy critique as a myopic focus on WEIRD (i.e., western, educated, industrialized, rich, and democratic) populations that calls into question the generalizability of a great deal of social science research (Henrich et al., 2010). As a step toward addressing this gap, our study (1) examines how internet users make decisions about OPE in a high-risk context (2) that is more representative of the vast majority of Internet users' experiences worldwide as compared to users in democratic contexts. Recognizing the context dependent nature of OPE is therefore a theoretical strength of our paper, addressing recent criticisms on political communication scholarship's theoretical weakness on the import of context (Rojas \& Valenzuela, 2019).

Our study addresses this gap by developing a citizen-centric theoretical framework centered on the psychological drivers of citizen OPE in non-democratic contexts and drawing upon risk and decision-making scholarship. Acts of OPE are low-cost, digitally-enabled, and personalized activities such as publicly sharing one's opinion or motivating others to do so within online networks with intentions including creating awareness about, or contributing to the solution of, politically relevant issues and 
events (Theocharis, 2015). In this sense, OPE allows for an autonomous, activismcentered citizenship, a concept that also receives attention by those who view expression as a precursor for engaging in more traditional, offline forms of political participation (e.g., Bode et al., 2014; Boulianne, 2015; Gil de Zuniga et al., 2014; Rojas \& Puig-i-Abril, 2009).

From this perspective, our theoretical framework and empirical study center on how an individual's anticipatory emotions (Loewenstein et al., 2001) toward OPE, and their risk assessment of doing such, influence their frequency of engaging in it. Furthermore, we test the extent to which the impact of anticipatory emotions and risk assessments on behavior is moderated by regime opposition by treating it as a potential proxy for context-specific vulnerability. Employing a three-wave online survey panel from the Turkish context, we examine the net effects of anticipatory emotions and risk assessment on frequency of OPE over a 9-month period. By doing so we make two major contributions. First, we increase our understanding of what influences citizens to engage in low-cost political expression enabled by SNSs but are "high-risk" in practice in the face of networked authoritarian governments' political and legal sanctions. In turn, by identifying such psychological processes, we deepen our understanding of the mechanisms by which networked authoritarian regimes, as differentiated from democratic regimes, influence online behavior and possible strategies for countering their repressive efforts.

\section{Cost and Risk As Non-Equivalent Concepts: The Case of Networked Authoritarianism}

Threats against authoritarian regimes' hold on power make state-sponsored harassment, intimidation, and punishment, that is, repression, more likely to take place (Davenport, 2007; Stern \& Hassid, 2012). Likewise, the threat posed by SNSs motivates authoritarian regimes to exert greater control over online spaces and thwart the mobilization potential of aggrieved citizens (e.g., Howard, 2010; Pearce \& Kendzior, 2012; Tufekci, 2017). This exercise of state power to create repressive online environments through legal, technical, or coercive means is what MacKinnon (2012) terms networked authoritarianism. Individuals in these high-risk contexts face the constant threat of having their activities tracked, being banned from certain online activities, and/or being punished by political, legal, or economic means.

Instead of following a predetermined set of rules regarding the timing, type, and/or intensity of online repression tactics, networked authoritarian governments often employ an unpredictable mix of technological and sociopolitical measures (Sanovich et al., 2018). This inconsistent repression is often driven by governments' immediate need to counter impromptu online dissent and/or collective action against the regime or to address a previously harmless-looking online activity (Roberts, 2020; Schedler, 2013). As for political expression, the ambiguity surrounding such case-by-case repression leaves citizens with no clear guidance about what is safe discourse while creating uncertainty about the consequences of expressive behavior (Stern \& Hassid, 2012). 
Eventually, these regimes' unpredictability maximizes the panopticon-like utility of their repression. The resulting uncertainty renders regimes capable of collecting information on the current and potential perpetrators, as well as causes of dissent, and obliges citizens to feel continually threatened by the asymmetrical information that governments can collect about their political behavior. The uncertainty, hence, allows governments to cost-effectively implement their disciplinary power over citizens without taking the time and effort to sanction every threat to their authority and legitimacy. Instead, by making governments' arbitrary implementation of punishment public to citizens, regimes make citizens aware that their government is capable of identifying and penalizing perpetrators if it desires.

As uncertainty is one of the defining traits of networked authoritarian contexts, therefore, our study's investigation centers on (a) how individuals interpret the severity and uncertainty dimensions associated with government repression of OPE, and (b) how individuals' interpretations influence their behavioral responses. Answering these questions significantly contributes to our knowledge of how authoritarian practices limit information and communication technologies' political capacity through technical, legal, or political means. This approach centers on the social-psychology of citizens' decision-making in these authoritarian contexts where the public's subjective perceptions are more predictive of online behavior than expert "objective" assessments (e.g., ratings from international organizations). We build on recent scholarship on the psychology of repression on how fear shapes citizens' perceptions about and engagement in anti-government political participation (Aldama et al., 2019; Young, 2019), and how perceptions about how much freedom citizens enjoy, rather than reality, influence online political behavior in authoritarian contexts (e.g., Behrouzian et al., 2016; Nisbet et al., 2017; Nisbet \& Stoycheff, 2013; Stoycheff \& Nisbet, 2014).

Our perspective is also consistent with the research on micro-mobilization processes in which cost and risk are considered critical, yet distinct, factors for determining whether aggrieved individuals engage in contentious politics (Bennett \& Segerberg, 2013; McAdam, 1986). In this framework, "cost" refers to the expenditure, such as time, effort, and skills required prior to the actualization of activism, whereas risk refers to the anticipated negative consequences (e.g., legal, social, physical, and/or financial sanctions) that may occur after such political activity has taken place. Hence, although either posting a supportive or a critical online comment about a repressive government are both low-cost activities (e.g., compared with joining a street protest), the latter poses greater risk to the individual making the comment depending on the political context.

There has been a great deal of attention to how the growth of SNSs has dramatically lowered the costs of online political expression. (e.g., Bode, 2017; Margetts et al., 2016; Vaccari et al., 2015). This scholarship primarily builds on the works linking traditional media consumption to political participation as tested predominately in democracies (e.g., Carpini et al., 2004; Eveland et al., 2003). Authoritarian contexts and the percentage of internet users residing in them, however, far outnumber democratic contexts, calling into question the wider generalizability of online political expression research centered on democratic contexts alone (Freedom on the Net, 2019; Henrich et al., 2010). 
This lacuna in the scholarship is important as political communication in democratic and authoritarian contexts vary substantially. For instance, from a normative perspective, democratic political communication environments encourage citizens to be active, informed, and expressive while highlighting the potential benefits of political behavior and mobilization. In contrast, authoritarian regimes focus on curtailing political mobilization, suppressing political opposition, and promoting a passive citizenry by definition (Linz, 2000). As a consequence, political communication environments focus on disseminating the regime's repressive discourse highlighting the potential risks of expressive behavior (e.g., Nisbet et al., 2017).

Accordingly, the academic scholarship falls short of adequately explaining the experience in authoritarian contexts given the lack of an emphasis on the distinction between what is required prior to (i.e., cost) versus what may happen after engaging in OPE (i.e., risk) from a citizen viewpoint. Similarly, although previous works on social movements acknowledge that low-cost political activities may result in harsh sanctions in compelling political opportunity structures despite the accessibility of resources (e.g. Bennett \& Segerberg, 2013; Earl \& Kimport, 2011), this has not been incorporated into the understanding on how individuals make decisions about engaging in obviously easy, yet potentially dangerous, forms of participation.

Therefore, exploring individuals' low-cost but high-risk acts of online expression under an authoritarian set of rules in greater detail provides a more nuanced understanding of the citizens' micro-mobilization experience in online settings. Thus, we focus on the following fundamental question: How do citizens navigate the tension between the desire to openly and freely express online political dissent and the potential negative consequences of online activism in networked authoritarian contexts where the low-cost online activities often exhibit high-risk for individuals?

\section{Hypothesizing Online Political Expression in Networked Authoritarian Contexts}

What sets networked authoritarian contexts apart from democratic contexts is the greater magnitude of possible negative consequences of engaging in OPE (e.g., being arrested vs. losing friends) and greater uncertainty of whether negative consequences may occur. From a citizen-centric risk perspective, these judgments of uncertainty and jeopardy — or risk assessment - inform citizens' decision-making and behaviors (Rosa, 2003). These risk assessments are subjective interpretations of the potential danger of objects, events or behaviors, and they rely on individuals' biased assessments of complex and vague risk "signals" found in their social environment (Slovic, 1992; Tversky \& Kahneman, 1974). Accordingly, by risk, we refer to the uncertainty that networked authoritarian regimes create about the potential legal, political, or physical consequences of citizen OPE.

However, beyond explicit assessments of risk, emotions also play a role in guiding rapid and efficient decision-making, especially in situations with a level of high uncertainty and limited amount of information to judge possible consequences (Finucane et al., 2000; Slovic et al., 2004). This affect-as-information framework asserts that feelings influence decision-making and behavior when they arise in 
response to the anticipated decision or behavior (Clore, 1992; Loewenstein et al., 2001). These anticipatory emotions are positive and negative affective responses to the uncertainty of possible future consequences of the decision or choice for the self (Baumgartner et al., 2008; Ortony et al., 1988). In other words, the degree of uncertainty of possible consequences drive these emotions with positive emotions increasing the likelihood of engaging in the behavior and negative emotions reducing it (Cooper \& Nisbet, 2016; Loewenstein et al., 2001; Roseman et al., 1996; Smith \& Ellsworth, 1985).

Though risk assessments and anticipatory emotions influence judgment and decision-making processes simultaneously and continuously (Chaiken \& Trope, 1999; Slovic et al., 2004), anticipatory emotions play a crucial role in fostering the accuracy and efficiency of the decisions made. This is because individuals process mental images associated with objects based on the affect with which they are tagged even when they are taking rational action (Damasio, 1994). Therefore, these anticipatory emotions serve as a mental shortcut that helps individuals, regardless of the extent to which they rely on the analytic mode, make sense of complex, risk-inducing situations (Finucane et al., 2000).

In this sense, readily available anticipatory emotions turn judgment and decisionmaking into an easier, more efficient process in the absence of motivation or resources to engage in a systematic and cognitively demanding process of risk calculation (Slovic et al., 2004). Hence, whereas activated negative emotions act as dispiriting cues that lead individuals to develop a pessimistic view of, and eventually refrain from, engaging in a behavior (Lerner \& Keltner, 2001), positive emotions make it easier to accept, fight against, and/or adopt an optimistic attitude toward it (Pearlman, 2013). At the same time, the stronger the risk assessment, the more pessimistic the individual becomes in respect to dealing with potential negative outcomes of the behavior. Thus, we posit:

H1: Positive anticipatory emotions associated with OPE will increase frequency of OPE.

H2: Negative anticipatory emotions associated with OPE will decrease frequency of OPE.

H3: Assessing greater risk of OPE will decrease frequency of OPE.

Intuitive, heuristic-based decision-strategies guide most political behaviors (Lau \& Redlawsk, 2006). This is especially true for relatively "low-cost" behaviors such as OPE that do not require a great deal of time, resources, or deliberation compared to physical activities like joining a street protest (Earl \& Kimport, 2011; Halupka, 2014). There is also growing interest on the role emotions play in individuals' social media experiences. With their increasingly polarized and uncivil nature (e.g., Coe et al., 2014), interactions on social media trigger politically relevant feelings, which become an accessible source for the rationalization of one's political reasoning (Garrett et al., 2019; Lodge \& Taber, 2013), and lead individuals to seek ways to alleviate or channel the resulting emotions (see Weeks \& Garrett, 2019). 
In this sense, when an individual's emotional reactions to political objects or situations result in fast, yet biased, responses, they may outpace more deliberative assessments of risk (Lodge \& Taber, 2005; Taber \& Young, 2013). These reactions result from individuals consulting the emotional pool more strongly and automatically compared to cognitive assessments (Zajonc, 1980). Moreover, when the resulting evaluations of the two modes diverge, emotions exert a greater influence on behavioral decisions (Loewenstein et al., 2001). Thus, in light of the existing risk research that acknowledges the "dance of affect and reason" (Finucane et al., 2003), while we hypothesize that both emotions and explicit risk assessments influence individuals' responses, we question whether anticipatory emotions will exhibit a stronger influence on the resulting behavioral response.

RQ1: Do positive and negative anticipatory emotions associated with OPE have a greater influence on the frequency of OPE than assessment of its risk?

Concepts like the representativeness heuristic, susceptibility and motivated reasoning are also of importance when understanding citizens' judgments about how likely the governing regime is to punish them. The representativeness heuristic concerns individuals' tendency to focus on the similarities between an event of interest and a higher category identified based on relevant salient dimensions when judging how likely the event is to occur (Tversky \& Kahneman, 1974). As a relevant concept, susceptibility is an important element in individuals' efforts to deal with threats. Perceived susceptibility to facing negative consequences is a crucial factor in subjective evaluations of perceived threats (Witte, 1994). Accordingly, an individual's judgment of the most susceptible citizens shapes the salient features ascribed to whom a regime targets, as well as evaluations of the extent to which they are similar to the members of the targeted group. In this process, however, individuals are unable to evaluate risk signals that carry susceptibility-related information in an unbiased manner. Rather, strongly held political beliefs will drive motivated reasoning about risk signals from political actors, creating a perceptual bias that may amplify or dampen the perceived risk (Kunda, 1990; Lodge \& Taber, 2013).

As a salient feature for networked authoritarianism, the level of regime opposition or support may influence citizens' perceived vulnerability in two main ways. First, those who support the regime may evaluate the most susceptible groups as substantively different from themselves unlike opponents who are likelier to share a key feature (i.e., not supporting the current government) with those who suffer from repression. Second, it is possible that, regime supporters see OPE repression as less strict than it should be. Since networked authoritarian governments often justify their restrictive practices by emphasizing the threats SNSs pose on national security, moral values etc. (Nisbet et al., 2017), unlike regime opponents, regime supporters may see repression as a necessary and appropriate way to address perceived threats. Accordingly, by treating regime opposition as a proxy for individuals' vulnerability to repression (i.e., the extent to which they are susceptible to being targeted by the regime's sanctions), we suggest that it is a contributory moderator of the relationship between risk components 
and OPE (Holbert \& Park, 2019). In other words, we hypothesize magnitude of the influence that anticipatory emotions and risk assessments exert on OPE will vary at different levels of regime opposition.

H5a: Individuals'opposition to the regime is a contributory moderator of the relationship between positive anticipatory emotions and the frequency of OPE such that the relationship is positive for both those with high and low regime opposition, but stronger for the latter.

H5b: Individuals' opposition to the regime is a contributory moderator of the relationship between the negative anticipatory emotions and the frequency of OPE such that the relationship is negative for both those with high and low regime opposition, but stronger for the former.

H5c: Individuals' opposition to the regime is a contributory moderator of the relationship between risk assessment and the frequency of OPE such that the relationship is negative for both those with high and low regime opposition, but stronger for the former.

\section{Methodology}

\section{Data Source and Study Context}

The data for the analysis were collected from a three-wave self-administered online survey conducted in Turkish. ${ }^{1}$ Respondents were recruited through a Turkish online commercial opt-in panel, and were Turkish-speaking adults over age 18 residing in Turkey. Survey participation eligibility was determined based on quotas for age, sex, employment status, and educational attainment in order to resemble Turkish Internet users' demographics.

Respondents took the first wave of the survey between April 29th and May 6th $(N=1,995)$, the second wave between June 8th and 15th $(N=922)$ and the third wave between November 5th and 19th, $2015(N=487) .{ }^{2}$ These dates were determined based on the scheduled elections in Turkey in 2015. The first and second waves were administered before and after the general parliamentary elections that took place on June 7 th, 2015. The third wave was administered after the snap parliamentary elections that were held on November 1st, 2015 after the coalition negotiations following the June elections were broken down (see Supplemental Appendix A for the descriptive statistics for each wave, and Supplemental Appendix B for those that dropped out in waves 2 and 3). ${ }^{3}$

As a result, the respondents took the survey in a highly politicized environment coupled with a worsening state of freedoms reflected in Turkey's Freedom House internet freedom classification moving from partly free to not free after 2015. The Turkish context, therefore, provides a more generalizable setting for examining OPE as it is representative of the vast majority of political regimes worldwide that are partly free (Freedom House, 2019).

This risk and uncertainty in the Turkish case provides a perfect setting for studying how individuals deal with the possibility of regime-sourced political and legal 
sanctions targeted at political dissent. Turkey has a long history of implementing a variety of media censorship tactics such as imprisonment of journalists, mass firings of media staff, criminalization of dissent, intimidation of anti-government media through legal measures (Esen \& Gumuscu, 2016; Yesil, 2016). The growth of social media in Turkey has made it an alternative platform for contentious political discourse challenging regime power at low-cost, ${ }^{4}$ highlighted by the 2013 Gezi Park protests (Chrona \& Bee, 2017; Haciyakupoglu \& Zhang, 2015).

In turn, Turkish government has become increasingly repressive towards online dissent and with hundreds of citizens detained, arrested or tracked for what they post on social media (see Yesil et al., 2017 for a review). There have been many prominent cases of journalists, activists, celebrities as well as ordinary citizens being prosecuted for their online posts in the surveys' timeframe. Some of these prosecutions (e.g., a former Miss Turkey who shared a poem, a family doctor who shared a meme juxtaposing a fantasy novel character to the President) received wide coverage on mass media domestically and internationally (Freedom House, 2016). Likewise, the Turkish government is a world leader in removal requests from Twitter accounting for $45 \%$ of requests in 2017 for example (Twitter, 2017).

\section{Analytical Strategy and Measures}

We employ fixed-effects panel regression which allows us to control for time-specific effects (i.e., between variation) and omitted variables at the individual level (Allison, 2009; Halaby, 2004). ${ }^{5}$ Our analytical strategy, thus, offers a conservative approach to making causal inferences, which cannot be effectively addressed in random-effects models in the presence of unobservable variables (Lee, 2002). Accordingly, we assess the net effect between the predictor and outcome variables with minimum bias resulting from time-invariant and unobserved characteristics. Tables 1 and 2 summarize the results of our separate fixed-effects regressions.

Our focal variables were positive and negative anticipatory emotions, risk assessment, regime opposition, and frequency of OPE. While we controlled for TV and newspaper use, attention to news, and internal political efficacy due to their influence on political participation (Shah et al., 2005), we excluded socio-demographics from the analyzes for being stable characteristics given our use of fixed-effects regression (see Supplemental Appendix A for complete question wording and descriptive statistics, and Supplemental Appendix D for the correlation matrix of variables included in the analyzes).

We measured OPE via respondents' self-reported frequency of engaging in expressive activities on social networking sites via three items (See Supplemental Appendix A for specific wording). The responses were collected on a seven-point scale ( $1=$ Never, $7=$ Daily) and averaged together with more frequent engagement in OPE coded high.

For the anticipatory emotions, the survey asked respondents how they feel about "openly sharing what they think about Turkish politics or political leaders with others on social media" via a selection of emotions used in PANAS scales of emotions on a seven-point scale $(1=$ Not at all, $7=$ Extremely $)$ with higher scores indicating greater 


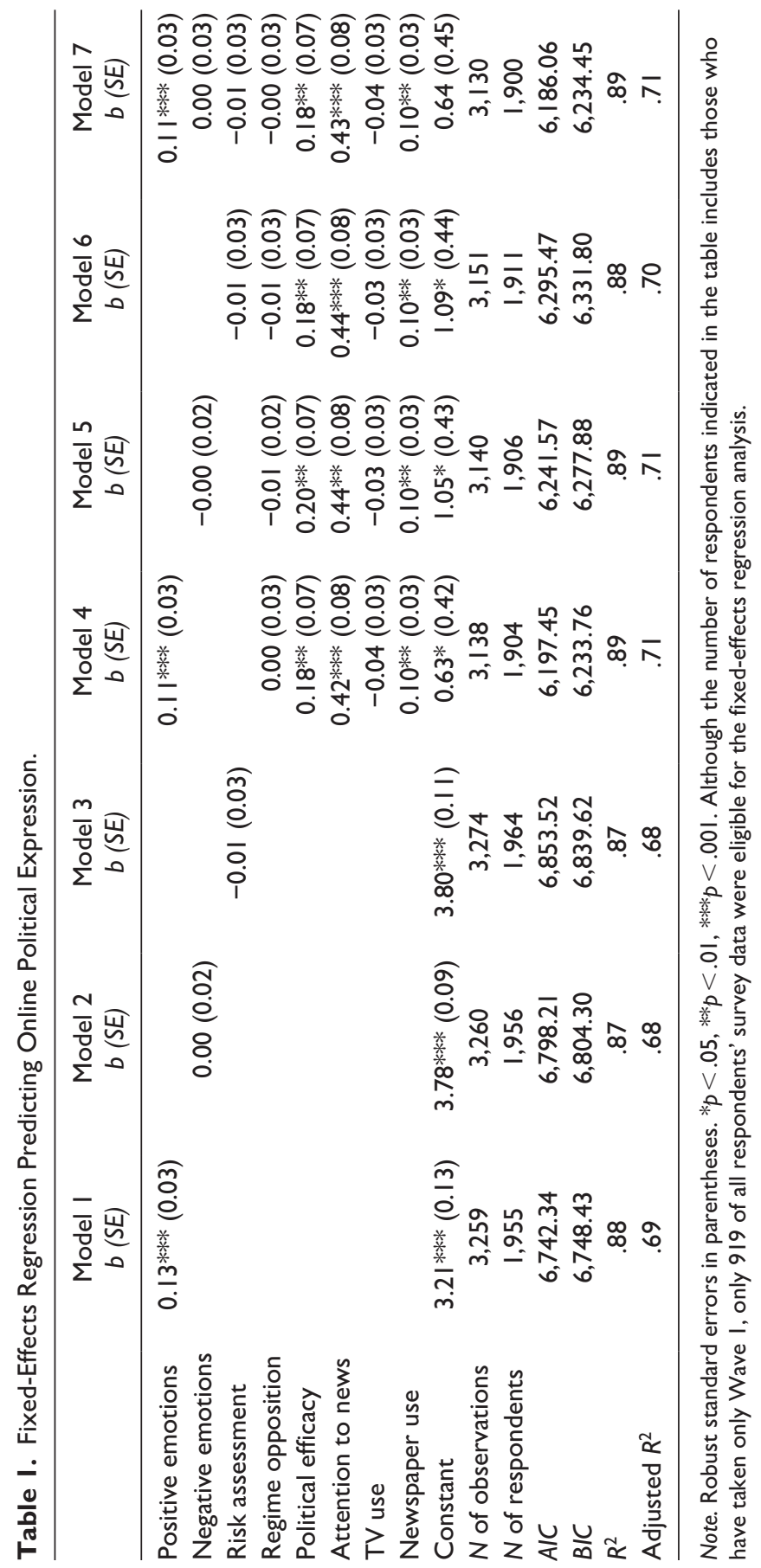




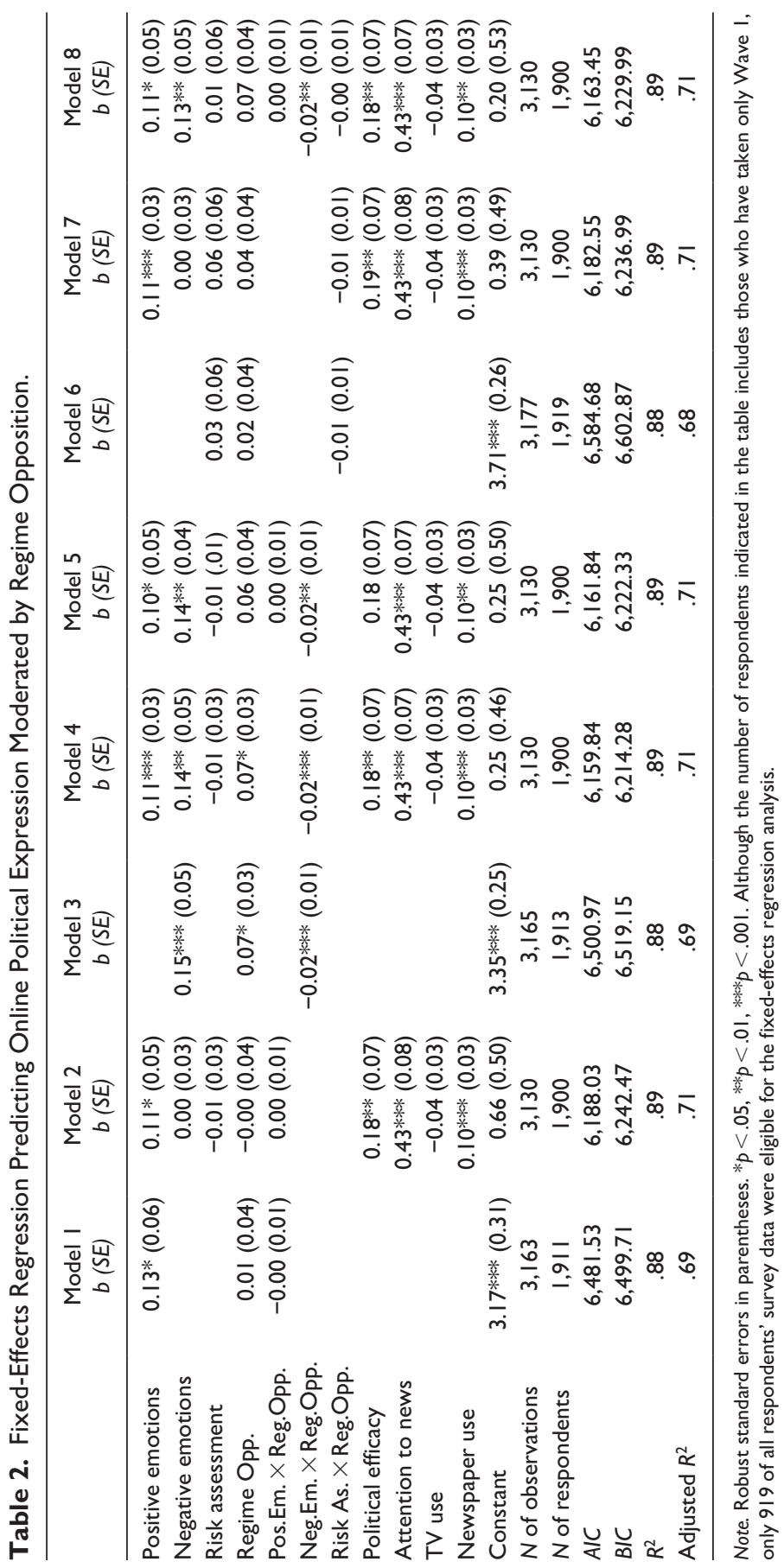


emotional experience (Watson et al., 1988). While we averaged the scores reported under "proud," "enthusiastic," "strong," "confident," and "excited" to construct the positive anticipatory emotions associated with OPE measure, we used those pertaining to "nervous," "worried," and "afraid" to measure negative anticipatory emotions associated with OPE. Responses were also submitted to a principal component factor analysis with varimax rotation to construct index standardized measures (see Supplemental Appendix C for factor loadings for each item). This ensured the construct validity for positive and negative emotions, which are treated as two distinct psychological constructs linked to psychodynamic sensitivity to signals of reward and punishment (Tellegen, 1985), respectively.

We measured risk assessment of OPE by asking respondents how much risk they think there is to engage in OPE. ${ }^{6}$ The same activities used in the OPE measure were listed along with a seven-point scale $(1=$ No risk at all, $7=$ Extreme amount of risk $)$. The responses to the three items were averaged to construct a single risk assessment measure with higher scores indicative of greater perceived risk.

Respondents' self-reported favorability towards the governing regime was used as a proxy for their regime opposition. Respondents were asked to report their favorability ratings of President Recep Tayyip Erdoğan, Prime Minister Ahmet Davutoğlu, and the governing Justice and Development Party (AKP) on an eleven-point scale $(0=$ Very unfavorable, $10=$ Very favorable). The responses were then recoded with higher scores indicative of less favorability, and averaged to construct a single measure of regime opposition.

Television and newspaper use for getting news and information were measured on seven-point scales ranging from " $1=$ Never" to " $7=$ Daily." Attention to politics was measured by averaging three survey questions (See Supplemental Appendix A) on five-point scales $(1=$ Not at all closely, $5=$ Extremely closely $)$. For measuring internal political efficacy, we used three five-point $(1=$ Strongly disagree, $5=$ Strongly agree $)$ items from Niemi et al.'s (1991) scale and averaged respondent's answers to construct the variable.

\section{Results}

The results of the fixed-effects model specifications employing the Turkish panel survey data are presented in Tables 1 and 2. In the first three models, positive and negative anticipatory emotions associated with OPE, and risk assessment of OPE were each separately entered as predictors of OPE as shown in Table 1. Next, time-variant control variables (attention to news, newspaper use, TV use, political efficacy, and regime opposition) were added to the fixed-effects models in order to account for alternative explanations for citizens' OPE. Finally, we investigated the moderating influence of regime opposition by introducing it as an interaction term to the models specified in Table 1. The results of the interaction models are reported in Table 2.

The initial results for the empty models as presented in Table 1 suggest that only positive emotions associated with OPE significantly predicted greater engagement in the behavior $(b=0.13, p<.001)$. Confirming H1, positive anticipatory emotion's 
significant influence on the frequency of OPE remained the same even when the time-variant control variables were added to the models (4 and 7) as shown in Table $1(b=0.11, p<.001)$. In these models, increase in attention to news $(b=0.42$, $p<.001)$, newspaper use $(b=0.10, p<.01)$, and political efficacy $(b=0.18, p<.01)$ were also significant predictors of more frequent OPE. Although the analyzes provided empirical support for $\mathrm{H} 1$, they failed to confirm $\mathrm{H} 2$ and $\mathrm{H} 3$. That is, while positive emotions associated with OPE influenced the frequency of engaging in it, negative emotions and risk assessment did not appear to have non-contingent influence on OPE.

However, this absence of a relationship in the model does not necessarily denote there is no relationship if the association between the predictor and outcome is contingent upon a third variable as we theorize (Hayes, 2017; Holbert \& Park, 2019). We tested, thus, for significant heterogeneity in the main effects of positive emotions, negative emotions, and risk assessments on frequency of OPE based on differing levels of opposition to the governing regime in our final set of analyzes. The results of the fixed-effects analyzes with the within-respondent change in regime opposition as the interaction term are presented in Table 2 . The findings revealed that regime opposition did not significantly moderate the influence of positive emotions and risk assessments on OPE, failing to support $\mathrm{H} 5 \mathrm{a}$ and $\mathrm{H} 5 \mathrm{c}$. That is, for both regime opponents and supporters, feeling positively led to more frequent OPE while greater risk assessment had no significant effects.

Interestingly, our results revealed heterogeneity in the main effects of negative emotions on OPE based on within-unit variation in regime opposition that revealed what is termed "transverse cleaved moderation" (see Holbert \& Park, 2019). The relationship between negative emotions and OPE such that the relationship was statistically significant and negative for regime opponents while statistically significant and positive for those with low regime opposition $(b=-0.02, p<.001)$. As illustrated in Figure 1, when the negative emotions associated with OPE were high, those with high regime opposition engaged in the behavior less frequently than those who support the regime. These findings suggest that negative anticipatory emotions did in fact influence the frequency of OPE but with opposing valence at different levels of regime opposition when they were high. The resulting transverse cleaved moderation, thus, provides partial support for $H 2$ and $H 5 \mathrm{~b}$ as negative emotions influence OPE as predicted but only for a subset of the online population most vulnerable to sanctionsthose most opposed to the governing regime.

Finally, RQ1 questioned whether anticipatory emotions will have a greater influence on OPE as compared to risk assessment. As Tables 1 and 2 demonstrate, unlike anticipatory emotions, risk assessment was a nonsignificant predictor across all models tested, including when positive and negative emotions were absent from the model.

The analyzes, in sum, provided empirical support for the role of anticipatory emotions in driving OPE as demonstrated via a panel survey conducted in a networked authoritarian context. Additionally, a robustness check was performed to see if the results would be different when only those who participated in all three waves were included in the analysis (see Supplemental Appendix E). The results produced similar 


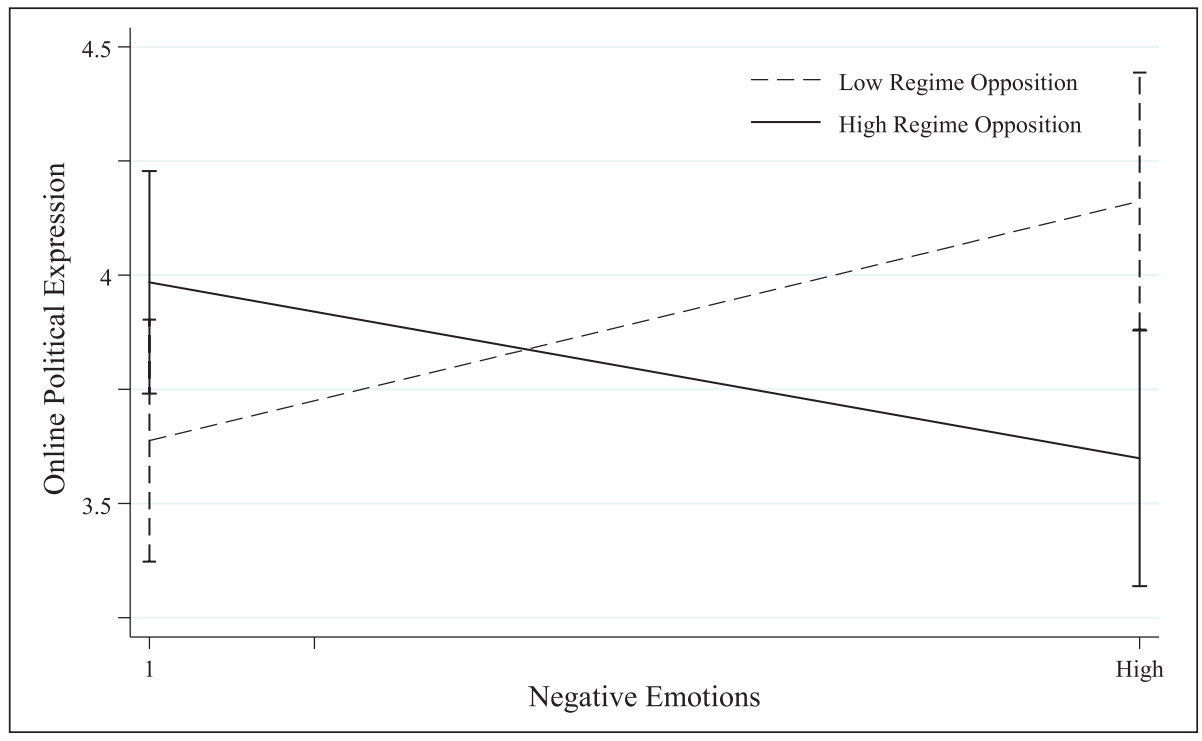

Figure I. Effect of negative anticipatory emotions on online political expression moderated by regime opposition $(95 \% \mathrm{Cls})$.

Note. The cutoff values for low and high regime opposition were determined by taking one standard deviation below and above the mean regime opposition as reference.

findings as the current study produced with the full sample in regard to testing the proposed hypotheses.

\section{Discussion}

\section{Methodological Considerations and Limitations}

Before discussing the theoretical and practical contributions of our tested theoretical framework, we note some methodological considerations and limitations to our study. Controlling for unobserved variables across survey waves in our analysis provides a conservative measure of our causal claims using non-experimental data, and ensures that our results are robust to disturbances that could have resulted from a survey period with two general elections. Using Turkey as the study context allows us to test our hypotheses in a political setting where both the uncertainty about the outcomes of OPE and a considerable level of mobilization in online information spaces exist simultaneously, due to the government's transitioning into increasingly heavier suppression of OPE at the time of data collection. In this sense, the government's unpredictable responses to political criticisms, which have become a part of citizens' daily life in the recent years, serve as a timely example of a risk environment where citizens have to navigate their way by relying on limited sources of information about the risks of political engagement. 
At the same time, we acknowledge the gradients of networked authoritarianism, and suggest that our hypotheses should be tested in other contexts that have different degrees of consequences for contentious expression as well as vary in the amount of vocal and mobilized opposition. Online political behavior was the focus of our study, and thus, our sampling centered on Turkish internet users. However, as a consequence, our analyzes are neither generalizable to all contexts and populations nor based on a nationally representative sample that includes both users and non-users. A possible limitation that arises is that the results may be subject to an under-coverage problem as those who potentially refrain from using the Internet due to regime repression are not included in the sample. Nevertheless, the use of fixed-effects panel regression significantly reduces this limitation by examining within-subject change over time.

We also recognize measurement-related limitations which one should consider when interpreting our results. First, compared to asking respondents how much risk they think there is in engaging in OPE in general, directly accounting for perceived vulnerability and susceptibility to different types of negative consequences with varying severity levels (e.g., getting arrested vs. losing friends) may deliver a more robust measure of risk assessment. This more robust measurement would allow us to better untangle the emotional and cognitive factors driving OPE, and thus, employ a more thorough investigation of our research question. Second, alternative ways of assessing regime opposition that take into consideration cognitive elements (e.g., satisfaction with, or assessment of, government performance) would also be beneficial.

\section{Theoretical Contributions and Pathways Forward}

Despite the interest in the role of SNSs in political mobilization, our knowledge is still highly limited with respect to the actual experiences of individuals who deal with daily uncertainties created by their governments' repressive strategies. In light of this knowledge hole, we contribute to the communication literature a more nuanced, yet more globally generalizable, theoretical framework for understanding how citizens negotiate the risks of engaging in low-cost political activities. Our findings offer valuable insights on the emotional and social-psychological processes that influence individual decisions to engage in contentious political behavior in a range of illiberal or authoritarian contexts around the globe, including Turkey (e.g., Capelos \& Chrona, 2018; Erișen, 2013; Morales, 2020; Muzammil \& Howard, 2013; Roberts, 2020; Skoric et al., 2016).

This study tested the how anticipatory emotions and risk perceptions associated the engaging in OPE within a networked authoritarian regime influence respondents' OPE self-reported behaviors. Our findings reveal that citizens' cognitive perceptions of risk associated with OPE are not associated with their behavioral response. As for emotions, the more positively individuals feel about OPE, the more frequently they engage in it. Moreover, the effect of negative emotions associated with OPE is moderated by regime opposition resulting in different levels of OPE when negative emotions are high. In other words, when both those with low and high regime opposition feel negatively about the behavior, the former engages in OPE more frequently than the latter 
which is not the case when the negative emotions are low. Put together, these results show that while risk assessment does not exhibit a significant influence on frequency of OPE, both positive and negative anticipatory emotions are predictive of how citizens respond to government online repression.

The study's results and implications also point to several pathways for future research. For instance, regime supporters engaging in more OPE (compared to regime opponents), even when feeling negatively about the behavior, deserves attention. A possible explanation for this finding are the differences in motivations for OPE between regime supports and opponents. Online political expression may be an opportunity for regime supporters to publicly signal their allegiance with the regime. That is, engaging in the behavior may reduce the chances of facing negative consequences for regime supporters as they can actively position themselves in the safe zone by contributing to pro-regime online presence. Thus, unlike regime opponents whose negative feelings lead to refraining from the behavior that would make them more vulnerable to repression, regime supporters may enjoy the possibility of strategically turning OPE into a tool to address their negative feelings about the behavior. This interaction illustrates the dual nature of negative emotions and uncertainty that networked authoritarian regimes may strategically employ. For example, creating high levels of negative emotions associated with online expression may diminish the prevalence of opposing views online while encouraging greater pro-regime signaling among supporters - creating online echo chambers that reinforce and support the governing regime's narratives. In turn, establishing a pro-government presence in online spaces while maintaining control over that of the opposition strengthens networked authoritarians' hand (Sanovich et al., 2018).

Another topic deserving more study is the role of online social environments in individuals' experiential decision-making mechanism. Online environments where a high number of others frequently stand up against political and legal restrictions on expression may lead to stronger positive emotions (e.g., feeling proud, confident, enthusiastic) associated with OPE, and enhance citizens' tolerance towards the risk of facing sanctions. Beyond feelings, at the cognitive level, witnessing widespread activism in one's social network may decrease the salience of the likelihood and severity of potential government sanctions at the time of making decisions to engage in contentious online expression.

In this sense, exposure to other citizens' OPE may not only create awareness of their discontent with the regime but also provide social proof about the resilience of the regime's efforts for discouraging online political contention from a preference falsification perspective (Cialdini, 2001; Kuran, 1997; Young, 2019). Such information may signal that platforms like social media provide freedom for the expression of grievances that remains unpunished. Individuals with such judgment may thus feel more optimistic regarding OPE upon observing others' behaviors notwithstanding the risks of facing negative sanctions.

Similarly, an individual's interpretation of the likelihood and severity of sanctions citizens face may influence the level of freedom they assign to online information spaces. Direct censorship practices are often invisible or unknown to a majority of citizens. In 
comparison, sanctioning citizens in highly visible ways allows regimes to create extremely vivid negative emotional cues about OPE. Diffused widely through mass media and online/offline social networks, the availability of such cues triggers negative feelings and associations that inhibit OPE due to the uncertainty over one's vulnerability or the severity of sanctions as compared to direct censorship. Therefore, considering the channels through which risk signals travel as well as get amplified (or attenuated) in authoritarian settings (e.g., mass media, social networks), a closer look on how individuals learn what they know about potential dangers of online political activism would provide valuable information for researchers and expand our knowledge on how mobilization around low-cost, high-risk activities takes place (Kasperson et al., 1988).

\section{Policy Implications}

Online political contention in networked authoritarian contexts is key to raising public awareness about censored topics, disseminating citizen-led issue frames, and activating participation thresholds. The activation of otherwise passive citizens is how political and social movements accelerate and strengthen their spread across groups and individuals (Barbera et al., 2015; Granovetter, 1978). We help unpack this process by demonstrating the role of emotions in driving OPE for both regime opponents and supporters alike. Our study reinforces the argument that "psychological firewalls" designed to retard online activism may be superior to "technical firewalls" such as content removal or access restrictions as a form of censorship (Nisbet et al., 2017).

To counter these practices, international and domestic pro-democracy forces have employed several strategies. The first, the most commonly utilized, may be labeled as an online "arms race" to improve circumvention tools that allow vulnerable users to more safely use online platforms for expression and information-seeking. However, in turn, networked authoritarian regimes develop their own methods to counter these tools. A second common strategy is building communication campaigns targeting vulnerable populations that inform them on digital safety practices and encourage selfefficacy in online platforms. The third strategy is policy-oriented and is to advocate for international online privacy standards that may constrain the ability of regimes to engage in these practices. Collectively, these strategies may retard network authoritarianism to some degree, but to keep the internet from being dominated by pro-repression actors, we argue that new innovative strategies and approaches are needed.

\section{Concluding Remarks}

Online political expression has predominately been explored within democratic political contexts that enjoy relatively low risk-meaning that these studies may not be generalizable to a global population residing mostly in illiberal or authoritarian contexts. In contrast, we recognize the context-dependent nature of OPE, and rigorously test a theoretical framework for understanding decision-making that takes into account the higher risks citizens face from networked authoritarian regimes. Our findings support our theoretical framework, highlight the influence of emotions, as compared to 
cognitive, processes in decision-making, and point to several promising pathways for future research on OPE across different political contexts.

\section{Declaration of Conflicting Interests}

The author(s) declared no potential conflicts of interest with respect to the research, authorship, and/or publication of this article.

\section{Funding}

The author(s) received no financial support for the research, authorship, and/or publication of this article.

\section{ORCID iD}

Aysenur Dal (iD) https://orcid.org/0000-0003-2868-0282

\section{Supplemental Material}

Supplemental material for this article is available online.

\section{Notes}

1. Questionnaire design and survey programming were done in Turkish by a native speaker.

2. Wave 1 sample size ensured a large effect size $\left(f^{2}=0.35\right)$ with an $\alpha=.05$ and power $=0.80$ with approximately $50 \%$ attrition expected between waves (Cohen, 1988).

3. Supplemental Appendix B provides descriptive statistics for those who dropped out of the panel at either Wave 1 or Wave 2. The level of similarity between those who dropped and those who remained indicates no observable common cause for the panels' unit nonresponse based on the socio-demographics as well as outcome and predictor variables.

4. Given the non-systematic, occasional, and limited nature of the obstacles Internet users face when accessing social media in Turkey at the time of data collection, we assume the cost of using such means for OPE as low.

5. In terms of control variables, we only account for time-varying variables and exclude timeinvariant socio-demographics from our analyzes. In so doing, we let each respondent be their own control regarding the stable, unobserved variables, and address the causality concerns that may arise due to our use of non-experimental survey data. We validate our panel data's suitability for fixed-effects regression using the Hausman statistic (1978) and report the coefficients with robust standard errors to address heteroskedasticity concerns.

6. We acknowledge that unlike anticipatory emotions, which we measured as an integral emotional response with a defined target object (Pham, 2007), our risk assessment measure refers to a more general object. Given that AKP has already been in power for 14 years at the time of data collection, we believe that a more specific object would potentially activate affect associated with the current government more so than how much risk one thinks there is in such behavior, confounding the measure.

\section{References}

Aldama, A., Vásquez-Cortés, M., \& Young, L. E. (2019). Fear and citizen coordination against dictatorship. Journal of Theoretical Politics, 31(1), 103-125. https://doi. org/10.1177/0951629818809425 
Allison, P. (2009). Fixed effects regression models. SAGE.

Barberá, P., Wang, N., Bonneau, R., Jost, J. T., Nagler, J., Tucker, J., \& González-Bailón, S. (2015). The critical periphery in the growth of social protests. PLoS One, 10(11), 1-15. https://doi.org/10.1371/journal.pone.0143611

Baumgartner, H., Pieters, R., \& Bagozzi, R. P. (2008). Future-oriented emotions: Conceptualization and behavioral effects. European Journal of Social Psychology, 38(4), 685-696. https://doi.org/10.1002/ejsp.467

Behrouzian, G., Nisbet, E. C., Dal, A., \& Çarkoğlu, A. (2016). Resisting censorship: How citizens navigate closed media environments. International Journal of Communication, 10, 23.

Bennett, W. L., \& Segerberg, A. (2013). The logic of connective action: Digital media and the personalization of contentious politics. Cambridge University Press.

Bode, L. (2017). Gateway political behaviors: The frequency and consequences of low-cost political engagement on social media. Social Media+ Society, 3(4), 1-10. https://doi. org/10.1177/2056305117743349

Bode, L., Vraga, E. K., Borah, P., \& Shah, D. V. (2014). A new space for political behavior: Political social networking and its democratic consequences. Journal of ComputerMediated Communication, 19(3), 414-429. https://doi.org/10.1111/jcc4.12048

Boulianne, S. (2015). Social media use and participation: A meta-analysis of current research. Information, Communication \& Society, 18(5), 524-538. https://doi.org/10.1080/13691 18X.2015.1008542

Capelos, T., \& Chrona, S. (2018). The map to the heart: An analysis of political affectivity in Turkey. Politics and Governance, 6(4), 144-158. https://doi.org/10.17645/pag.v6i4.1576

Carpini, M. X. D., Cook, F. L., \& Jacobs, L. R. (2004). Public deliberation, discursive participation, and citizen engagement: A review of the empirical literature. Annual Review of Political Science, 7, 315-344. https://doi.org/10.1146/annurev.polisci.7.121003.091630

Chaiken, S., \& Trope, Y. (1999). Dual-process theories in social psychology. Guilford Press.

Chrona, S., \& Bee, C. (2017). Right to public space and right to democracy: The role of social media in Gezi Park. Research and Policy on Turkey, 2(1), 49-61. https://doi.org/10.1080/ 23760818.2016.1272267

Cialdini, R. B. (2001). The science of persuasion. Scientific American, 284(2), 76-81.

Clore, G. L. (1992). Cognitive phenomenology: Feelings and construction of judgment. The Construction of Social Judgments, 10, 133-163.

Coe, K., Kenski, K., \& Rains, S. A. (2014). Online and uncivil? Patterns and determinants of incivility in newspaper website comments. Journal of Communication, 64(4), 658-679. https://doi.org/10.1111/jcom.12104

Cohen, J. (1988). Statistical power analysis for the behavioral sciences (2nd ed.). Lawrence Erlbaum Associates.

Cooper, K. E., \& Nisbet, E. C. (2016). Green narratives: How affective responses to media messages influence risk perceptions and policy preferences about environmental hazards. Science Communication, 38(5), 626-654. https://doi.org/10.1177/1075547016666843

Damasio, A. R. (1994). Descartes' error: Emotion, reason, and the human brain. Avon.

Davenport, C. (2007). State repression and political order. Annual Review of Political Science, 10, 1-23. https://doi.org/10.1146/annurev.polisci.10.101405.143216

Earl, J., \& Kimport, K. (2011). Digitally enabled social change: Activism in the internet age. MIT Press.

Erişen, C. (2013). Emotions as a determinant in Turkish political behavior. Turkish Studies, 14(1), 115-135. https://doi.org/10.1080/14683849.2013.766987 
Esen, B., \& Gumuscu, S. (2016). Rising competitive authoritarianism in Turkey. Third World Quarterly, 37(9), 1581-1606. https://doi.org/10.1080/01436597.2015.1135732

Eveland, W. P. Jr., Shah, D. V., \& Kwak, N. (2003). Assessing causality in the cognitive mediation model: A panel study of motivations, information processing, and learning during campaign 2000. Communication Research, 30(4), 359-386. https://doi.org/10.1177 /0093650203253369

Finucane, M. L., Alhakami, A., Slovic, P., \& Johnson, S. M. (2000). The affect heuristic in judgments of risks and benefits. Journal of Behavioral Decision Making, 13(1), 1-17.

Finucane, M. L., Peters, E., \& Slovic, P. (2003). Judgment and decision making: The dance of affect and reason. In S. L. Schneider \& J. Shanteau (Eds.). Emerging Perspectives on Judgment and Decision Research (pp. 327-364). Cambridge University Press.

Freedom House. (2016). Freedom on the net. Retrieved from https://freedomhouse.org/report/ freedom-net/freedom-net-2016

Freedom House. (2019). Freedom on the net. https://freedomhouse.org/report/freedom-net /2019/crisis-social-media

Garrett, R. K., Long, J. A., \& Jeong, M. S. (2019). New evidence on group polarization from partisan media to misperception: Affective polarization as mediator. Journal of Communication, 69(5), 490-517. https://doi.org/10.1093/joc/jqz028

Gil de Zúñiga, H., Molyneux, L., \& Zheng, P. (2014). Social media, political expression, and political participation: Panel analysis of lagged and concurrent relationships. Journal of Communication, 64(4), 612-634. https://doi.org/10.1111/jcom.12103

Granovetter, M. (1978). Threshold models of collective behavior. American Journal of Sociology, 83(6), 1420-1443.

Gunitsky, S. (2015). Corrupting the cyber-commons: Social media as a tool of autocratic stability. Perspectives on Politics, 13(1), 42-54. https://doi.org/10.1017/S1537592714003120

Haciyakupoğlu, G., \& Zhang, W. (2015). Social media and trust during the Gezi protests in Turkey. Journal of Computer-Mediated Communication, 20(4), 450-466. https://doi. org/10.1111/jcc4.12121

Halaby, C. N. (2004). Panel models in sociological research: Theory into practice. Annual Review of Sociology, 30, 507-544. https://doi.org/10.1146/annurev.soc.30.012703.110629

Halupka, M. (2014). Clicktivism: A systematic heuristic. Policy \& Internet, 6(2), 115-132. https://doi.org/10.1002/1944-2866.POI355

Hausman, J. D. (1978). Specification tests in econometrics. Econometrica, 46, 1251-1272.

Hayes, A. F. (2017). Introduction to mediation, moderation, and conditional process analysis (2nd ed.). Guilford.

Henrich, J., Heine, S. J., \& Norenzayan, A. (2010). The weirdest people in the world? Behavioral and Brain Sciences, 33(2-3), 61-83. https://doi.org/10.1017/S0140525X0999152X

Holbert, R. L., \& Park, E. (2019). Conceptualizing, organizing, and positing moderation in communication research. Communication Theory, 1-20. https://doi.org/10.1093/ct/qtz006

Howard, P. N. (2010). The digital origins of dictatorship and democracy. Oxford University Press.

Kasperson, R. E., Renn, O., Slovic, P., Brown, H. S., Emel, J., Goble, R., Kasperson, J. X., \& Ratick, S. (1988). The social amplification of risk: A conceptual framework. Risk Analysis, 8(2), 177-187. https://doi.org/10.1111/j.1539-6924.1988.tb01168.x

Kunda, Z. (1990). The case for motivated reasoning. Psychological Bulletin, 108(3), 480-498. https://doi.org/10.1037/0033-2909.108.3.480

Kuran, T. (1997). Private truths, public lies: The social consequences of preference falsification. Harvard University Press. 
Lau, R. R., \& Redlawsk, D. P. (2006). How voters decide: Information processing during election campaigns. Cambridge University Press.

Lee, M. J. (2002). Panel data econometrics: Methods-of-moments and limited dependent variables. Academic Press.

Lerner, J. S. \& Keltner, D. (2001). Fear, anger, and risk. Journal of Personality and Social Psychology, 81(1), 146-159. https://doi.org/10.1037/0022-3514.81.1.146

Linz, J. J. (2000). Totalitarian and authoritarian regimes. Lynne Reiner Publishers.

Lodge, M., \& Taber, C. S. (2005). The automaticity of affect for political leaders, groups, and issues: An experimental test of the hot cognition hypothesis. Political Psychology, 26(3), 455-482. https://doi.org/10.1111/j.1467-9221.2005.00426.x

Lodge, M., \& Taber, C. S. (2013). The rationalizing voter. Cambridge University Press.

Loewenstein, G. F., Weber, E. U., Hsee, C. K., \& Welch, N. (2001). Risk as feelings. Psychological Bulletin, 127(2), 267-286. https://doi.org/10.1037/0033-2909.127.2.267

MacKinnon, R. (2011). Liberation technology: China's "networked authoritarianism." Journal of Democracy, 22(2), 32-46. https://doi.org/10.1353/jod.2011.0033

MacKinnon, R. (2012). Consent of the networked: The worldwide struggle for Internet freedom. Basic Books.

Margetts, H., John, P., Hale, S., \& Yasseri, T. (2016). Political turbulence: How social media shape collective action. Princeton University Press.

McAdam, D. (1986). Recruitment to high-risk activism: The case of freedom summer. American Journal of Sociology, 92(1), 64-90. https://doi.org/10.1086/228463

Morales, J. S. (2020). Perceived popularity and online political dissent: Evidence from Twitter in Venezuela. The International Journal of Press Politics, 25(1), 5-27. https://doi. org/10.1177/1940161219872942

Morozov, E. (2011). The net delusion: The dark side of Internet freedom. PublicAffairs.

Muzammil, H. M., \& Howard, P. N. (2013). Democracy's fourth wave? Digital media and Arab Spring. Oxford University Press.

Niemi, R. G., Craig, S. C., \& Mattei, F. (1991). Measuring internal political efficacy in the 1988 National Election Study. American Political Science Review, 85(4), 1407-1413. https://doi. org/10.2307/1963953

Nisbet, E. C., Kamenchuk, O., \& Dal, A. (2017). A psychological firewall? Risk perceptions and public support for online censorship in Russia. Social Science Quarterly, 98(3), 958975. https://doi.org/10.1111/ssqu. 12435

Nisbet, E. C., \& Stoycheff, E. (2013). Let the people speak: A multi-level model of supply and demand for press freedom. Communication Research, 40(5), 720-741. https://doi. org/10.1177/0093650211429117

Ortony, A., Clore, G., \& Collins, A. (1988). The cognitive structure of emotions. Cambridge University Press.

Pearce, K. E., \& Kendzior, S. (2012). Networked authoritarianism and social media in Azerbaijan. Journal of Communication, 62(2), 283-298. https://doi.org/10.1111/j.14602466.2012.01633.x

Pearlman, W. (2013). Emotions and the microfoundations of the Arab uprisings. Perspectives on Politics, 11(2), 387-409. https://doi.org/10.1017/S1537592713001072

Pew Research Institute. (2015). Pew global attitudes project. http://www.pewglobal.org/

Pham, M. T. (2007). Emotion and rationality: A critical review and interpretation of empirical evidence. Review of General Psychology, 11(2), 155-178. https://doi.org/10.1037/10892680.11.2.155 
Roberts, M. E. (2020). Resilience to online censorship. Annual Review of Political Science, 23(1), 401-419. https://doi.org/10.1146/annurev-polisci-050718-032837

Rød, E. G., \& Weidmann, N. B. (2015). Empowering activists or autocrats? The internet in authoritarian regimes. Journal of Peace Research, 52(3), 338-351. https://doi.org/10.1177 /0022343314555782

Rojas, H., \& Puig-i-Abril, E. (2009). Mobilizers mobilized: Information, expression, mobilization and participation in the digital age. Journal of Computer-Mediated Communication, 14(4), 902-927. https://doi.org/10.1111/j.1083-6101.2009.01475.x

Rojas, H., \& Valenzuela, S. (2019). A call to contextualize public opinion-based research in political communication. Political Communication, 36(4), 652-659. https://doi.org/10.10 $80 / 10584609.2019 .1670897$

Rosa, E. A. (2003). The logical structure of the social amplification of risk framework (SARF): Metatheoretical foundation and policy implications. In N. K. Pidgeon, R. E. Kasperson \& P. Slovic (Eds.), The social amplification of risk (pp. 47-79). Cambridge University Press.

Roseman, I. J., Antoniou, A. A., \& Jose, P. E. (1996). Appraisal determinants of emotions: Constructing a more accurate and comprehensive theory. Cognition and Emotion, 10(3), 241-277. https://doi.org/10.1080/026999396380240

Sanovich, S., Stukal, D., \& Tucker, J. A. (2018). Turning the virtual tables: Government strategies for addressing online opposition with an application to Russia. Comparative Politics, 50(3), 435-482. https://doi.org/10.5129/001041518822704890

Schedler, A. (2013). The politics of uncertainty: Sustaining and subverting electoral authoritarianism. Oxford University Press.

Shah, D. V., Cho, J., Eveland, W. P. Jr., \& Kwak, N. (2005). Information and expression in a digital age: Modeling internet effects on civic participation. Communication Research, 32(5), 531-565. https://doi.org/10.1177/0093650205279209

Skoric, M. M., Zhu, Q., \& Pang, N. (2016). Social media, political expression, and participation in Confucian Asia. Chinese Journal of Communication, 9(4), 331-347. https://doi.org/10. 1080/17544750.2016.1143378

Slovic, P. (1992). Perception of risk: Reflections on the psychometric paradigm. In S. Krimsky \& D. Golding (Eds.), Social theories of risk (pp. 117-152). Praeger.

Slovic, P., Finucane, M. L., Peters, E., \& MacGregor, D. G. (2004). Risk as analysis and risk as feelings: Some thoughts about affect, reason, risk, and rationality. Risk Analysis, 24(2), 311-322. https://doi.org/10.1111/j.0272-4332.2004.00433.x

Smith, C. A., \& Ellsworth, P. C. (1985). Patterns of cognitive appraisal in emotion. Journal of Personality and Social Psychology, 48, 813-838.

Stern, R. E., \& Hassid, J. (2012). Amplifying silence: Uncertainty and control parables in contemporary China. Comparative Political Studies, 45(10), 1230-1254. https://doi. org/10.1177/0010414011434295

Stoycheff, E., \& Nisbet, E. C. (2014). What's the bandwidth for democracy? Deconstructing internet penetration and citizen attitudes about governance. Political Communication, 31(4), 628-646. https://doi.org/10.1080/10584609.2013.852641

Taber, C. S., \& Young, E. (2013). Political information processing. In L. Huddy, D. O. Sears \& J. S. Levy (Eds.), The Oxford handbook of political psychology (2nd ed., pp. 525-558). Oxford University Press.

Tellegen, A. (1985). Structures of mood and personality and their relevance to assessing anxiety, with an emphasis on self-report. In A. H. Tuma \& J. D. Maser (Eds.), Anxiety and the anxiety disorders (pp. 681-706). Lawrence Erlbaum Associates, Inc. 
Theocharis, Y. (2015). The conceptualization of digitally networked participation. Social Media + Society, 1(2), 1-14. https://doi.org/10.1177/2056305115610140

Tremblay, P. (2015, December 7) Is Gollum good? Turkish judge consults "TV expert" to find out. Al Monitor. https://www.al-monitor.com/pulse/sites/almonitor/contents/articles/originals/2015/12/turkey-lord-of-the-rings-gollum-under-investigation.ac.html

Tufekci, Z. (2017). Twitter and tear gas: The power and fragility of networked protest. Yale University Press.

Tversky, A., \& Kahneman, D. (1974). Judgment under uncertainty: Heuristics and biases. Science, 185(4157), 1124-1131.

Twitter Transparency Report. (2017). https://transparency.twitter.com

Vaccari, C., Valeriani, A., Barberá, P., Bonneau, R., Jost, J. T., Nagler, J., \& Tucker, J. A. (2015). Political expression and action on social media: Exploring the relationship between lower-and higher-threshold political activities among Twitter users in Italy. Journal of Computer-Mediated Communication, 20(2), 221-239. https://doi.org/10.1111/jcc4.12108

Watson, D., Clark, L. A., \& Tellegen, A. (1988). Development and validation of brief measures of positive and negative affect: The PANAS scales. Journal of Personality and Social Psychology, 54(6), 1063-1070. https://doi.org/10.1037//0022-3514.54.6.1063

Weeks, B. E., \& Garrett, R. K. (2019). Emotional characteristics of social media and political misperceptions. In J. E. Katz \& K. K. Mays (Eds.), Journalism \& truth in an age of social media (pp. 236-250). Oxford University Press.

Witte, K. (1994). Fear control and danger control: A test of the extended parallel process model (EPPM). Communications Monographs, 64(2), 113-134. https://doi.org/10.1080 /03637759409376328

Yesil, B. (2016). Media in new Turkey: The origins of an authoritarian neoliberal state. University of Illinois Press.

Yesil, B., Sözeri, E. K., \& Khazraee, E. (2017). Turkey's internet policy after the coup attempt: The emergence of a distributed network of online suppression and surveillance. http://globalnetpolicy.org/wpcontent/uploads/2017/02/Turkey1_v6-1.pdf

Young, L. E. (2019). The psychology of state repression: Fear and dissent decisions in Zimbabwe. American Political Science Review, 113(1), 140-155. https://doi.org/10.1017/ S000305541800076X

Zajonc, R. B. (1980). Feeling and thinking: Preferences need no inferences. American Psychologist, 35(2), 151-175.

\section{Author Biographies}

Aysenur Dal is an assistant professor in the Department of Communication and Design at Bilkent University, Ankara, Turkey. Her research interests center on political communication, public opinion, social-psychological dynamics of social media activities, risk perceptions, digital privacy and social networks.

Erik C. Nisbet is an associate professor and Owen L. Coon Endowed Professor of Policy Analysis \& Communication in the School of Communication at Northwestern University, Evanston, Illinois. His research interests focus on communication, public policy, and public opinion with a focus on science and environmental policy, democratic governance and international conflict. 